\title{
Review Article \\ Redox-Dependent Effects in the Physiopathological Role of Bile Acids
}

\author{
Josué Orozco-Aguilar $\mathbb{D}^{1,2,3}$ Felipe Simon $\mathbb{D}^{2,4,5}$ and Claudio Cabello-Verrugio $\mathbb{D}^{1,2,3}$ \\ ${ }^{1}$ Laboratory of Muscle Pathology, Fragility, and Aging, Department of Biological Sciences, Faculty of Life Sciences, \\ Universidad Andres Bello, Santiago 8370146, Chile \\ ${ }^{2}$ Millennium Institute on Immunology and Immunotherapy, Santiago 8370146, Chile \\ ${ }^{3}$ Center for the Development of Nanoscience and Nanotechnology (CEDENNA), Universidad de Santiago de Chile, \\ Santiago 8350709, Chile \\ ${ }^{4}$ Millennium Nucleus of Ion Channel-Associated Diseases (MiNICAD), Universidad de Chile, Santiago 8370146, Chile \\ ${ }^{5}$ Laboratory of Integrative Physiopathology, Department of Biological Sciences, Faculty of Life Sciences, Universidad Andres Bello, \\ Santiago 8370146, Chile
}

Correspondence should be addressed to Claudio Cabello-Verrugio; claudio.cabello@unab.cl

Received 6 May 2021; Accepted 17 August 2021; Published 6 September 2021

Academic Editor: Anwen Shao

Copyright (C) 2021 Josué Orozco-Aguilar et al. This is an open access article distributed under the Creative Commons Attribution License, which permits unrestricted use, distribution, and reproduction in any medium, provided the original work is properly cited.

\begin{abstract}
Bile acids (BA) are recognized by their role in nutrient absorption. However, there is growing evidence that BA also have endocrine and metabolic functions. Besides, the steroidal-derived structure gives BA a toxic potential over the biological membrane. Thus, cholestatic disorders, characterized by elevated BA on the liver and serum, are a significant cause of liver transplant and extrahepatic complications, such as skeletal muscle, central nervous system (CNS), heart, and placenta. Further, the BA have an essential role in cellular damage, mediating processes such as membrane disruption, mitochondrial dysfunction, and the generation of reactive oxygen species (ROS) and oxidative stress. The purpose of this review is to describe the $\mathrm{BA}$ and their role on hepatic and extrahepatic complications in cholestatic diseases, focusing on the association between $\mathrm{BA}$ and the generation of oxidative stress that mediates tissue damage.
\end{abstract}

\section{Introduction}

Bile acids (BA) are a group of steroidal molecules derived from cholesterol. These molecules have been historically described as solubilizing agents for lipids and activators for pancreatic enzymes, supporting their role in intestinal absorption $[1,2]$. While the BA are intrinsically toxic in elevated concentrations due to the amphipathic structure, several antecedents indicate that BA also have endocrine and metabolic functions. Furthermore, despite their steroidal nature, the BA stereochemistry differs from other steroids, such as steroidal hormones. Therefore the receptor and signaling vary $[3,4]$.

Cholestatic liver diseases and the complications derived from the gradual destruction of bile ducts produce BA accu- mulation in the liver. This increment of BA induces a proinflammatory response and an increased production of reactive oxygen species (ROS), leading to cellular damage. Cholestatic pathologies do not have effective treatments, making them one of the leading causes of liver transplants [5-7].

Several pathological conditions, endogenous or xenobiotic-induced, might generate the obstruction of bile flow, elevating the BA concentrations within hepatocytes and serum and damaging the neighboring tissues $[6,8,9]$. In this line, the BA-dependent cytotoxicity and cellular alterations are associated with oxidative stress, mainly affecting the liver and extrahepatic tissues such as the heart, skeletal muscle, and placenta. In the central nervous system (CNS), contradictory effects of BA and their receptors reportedly show generation or prevention of oxidative stress [10-12]. 
TABLE 1: The general structure of more abundant bile acids in humans.

Bile acid
Cholic acid
Deoxychodeoxycholic acid
Lithocholic acid

This review presents a description of BA and their primary receptors, their clinical association with cholestatic diseases, and the impact of BA-induced oxidative stress observed in critical tissues.

\section{Bile Acids}

BA are amphiphilic molecules that belong to the acidic sterol family. They have a unique stereochemistry, hydroxyl groups, and an aliphatic side chain with a terminal carboxyl residue. All hydroxyl groups and the side carboxyl group are faced in the same plane, except in ursodeoxycholic acid (UDCA) (Table 1), forming a structure with opposing lipophilic properties [13]. BA correspond to the bile's significant lipidic component and are synthesized from cholesterol in the liver and secreted to store in the gallbladder $[1,13]$. De novo synthesized BA, such as cholic acid (CA) and chenodeoxycholic acid (CDCA), are categorized as primary and are the most abundant species in humans. The primary BA can be conjugated with glycine or taurine at the side chain, increasing the water solubility before secretion into the canalicular duct. After the release into the small intestine, primary BA can be dehydroxylated by the intestinal microbiota, converting CA and CDCA into the secondary BA deoxycholic acid (DCA) and lithocholic acid (LCA), respectively. Also, the 7-hydroxyl group in CDCA can be epimerized to form the UDCA [4, 13-15].

The BA form micelles (in concentrations between 1 and $20 \mu \mathrm{M}$ ) with hydrophobic compounds, facilitating absorption processes at the intestine. Besides, lipid absorption is favored by BA-dependent pancreatic lipase activation $[14,16]$. Then, unconjugated and conjugated $\mathrm{BA}$ are reabsorbed in the small intestine and colon via passive and active transport back to the liver, completing the enterohepatic circulation $[13,16]$.
Further, BA have endocrine/metabolic functions, regulating their synthesis, transport, and detoxification; mediating the cellular energetics and lipid and glucose homeostasis; and modulating the intestinal microbiota $[7,13,14,16,17]$.

Alterations in BA metabolism and transport lead to pathological conditions. For example, high levels of BA in enterohepatic circulation can damage the liver and intestine, generating jaundice, cholesterol gallstones, and cholestatic liver diseases. Conversely, BA deficiency leads to nutrient malabsorption and fat-soluble vitamin deficiency $[1,7,13,18]$. Both extreme situations highlight the importance of a balanced BA metabolism due to their significant role in corporal homeostasis.

\section{Bile Acid Receptors}

The amphipathic nature of BA has been used to describe their significant physiological properties. However, the metabolic role of bile acids has been described mainly by discovering diverse receptors [1].

The BA receptors can be classified into two major groups: the nuclear and G-protein-coupled receptors. Below, we focused on the most widely described receptors, the farnesoid X receptor (FXR) and Takeda-G-protein-receptor-5 (TGR5) receptor, mentioning other receptors with a lesser expression and minor characterization in the literature (Table 2).

3.1. Farnesoid X Receptor. Initially, the FXR was recognized as a receptor for farnesol and some related metabolites. It forms a heterodimeric complex with the retinoid $\mathrm{X}$ receptor. In 1999, it was reported that BA are the physiologic ligands of FXR by three independent groups. The ligand-receptor interaction is independent of the conjugation status of BA, whereas the affinity of this interaction is determined by the substitutions in carbon 7 of BA [19-21]. FXR is encoded 
TABLE 2: Bile acid receptor distribution and ligands.

\begin{tabular}{|c|c|c|c|c|}
\hline Receptor & Classification & Distribution & Main agonist & References \\
\hline FXR & Nuclear receptor & $\begin{array}{c}\text { Liver and intestine } \\
\text { Minor expression in the heart, kidneys, CNS, } \\
\text { white adipose tissue, adrenal gland, pancreas, } \\
\text { and placenta }\end{array}$ & $\begin{array}{c}\mathrm{CDCA}>\mathrm{LCA}=\mathrm{DCA}>\mathrm{A} \\
7 \alpha-\mathrm{OH} \gg 7 \text {-keto } \gg 7 \beta-\mathrm{OH}\end{array}$ & {$[4,20,69]$} \\
\hline PXR & Nuclear receptor & $\begin{array}{c}\text { Liver and intestine } \\
\text { Kidney, stomach, and CNS }\end{array}$ & $\mathrm{LCA} \approx \mathrm{CDCA} \approx \mathrm{CDA}$ & {$[61,64]$} \\
\hline CAR & Nuclear receptor & Liver, kidney, CNS, and adrenal gland & LCA & {$[65]$} \\
\hline VDR & Nuclear receptor & Small intestine, colon, skin, heart, and kidney & LCA and metabolite & {$[67,70]$} \\
\hline TGR5 & $\begin{array}{l}\text { G-protein-coupled } \\
\text { receptor }\end{array}$ & $\begin{array}{l}\text { Heart, skeletal muscle, lung, spleen, kidney, liver, } \\
\text { CNS, enteric nervous system, gastrointestinal } \\
\text { tract, placenta, and adipocytes }\end{array}$ & $\mathrm{LCA}>\mathrm{DCA}>\mathrm{UDCA}>\mathrm{CDCA}>\mathrm{CA}$ & {$[10,40,46,47,71]$} \\
\hline S1PR2 & $\begin{array}{l}\text { G-protein-coupled } \\
\text { receptor }\end{array}$ & $\begin{array}{c}\text { Liver, small intestine, CNS, and enteric } \\
\text { nervous system }\end{array}$ & Conjugated DCA $\approx$ conjugated $\mathrm{CA}$ & {$[72,73]$} \\
\hline
\end{tabular}

by the $f x r$ gene that generates four transcripts' variants, all responsive to BA [22]. Another gene in mammals, $f x r \beta$ (pseudogene in humans and primates), expresses the FXR $\beta$ receptor that senses mainly lanosterol, and to a minor extent, BA [23].

FXR is involved in the metabolism and regulation of BA levels. Thus, FRX diminishes BA synthesis by repressing the critical enzyme expression associated with this process, such as cytochrome (CYP) 7a1 and 12- $\alpha$-hydroxylase [3, 24-26]. Also, FXR decreased intracellular levels of BA in hepatocytes by two mechanisms: downregulating the uptake transporters (SLCA1 and SLCO1A2) and upregulating the levels of efflux transporters (BSEP, MRP2, and OST $\alpha$ ) [27-30]. Furthermore, FXR diminishes the intestinal absorption of BA by inhibiting the expression of apical sodium-dependent BA transporter, an uptake transporter from enterocytes in the ileum, colon, and jejunum [31].

FXR is also related to a protective effect in several tissues. For example, the absence of FXR expression has been associated with vacuolization and hepatocyte hypertrophy, and also with increased serum triglyceride, cholesterol, glucose, and BA (resulting in mild cholestasis) [3, 32-34]. Also, the absence of FXR expression affected cardiac function and elevated the levels of myocardial injury markers associated with a BA overload [35]. Similarly, in a diabetes mice model, the FXR knock-out aggravates cardiac fibrosis and lipid accumulation [36]. Furthermore, FXR agonists diminish cardiac fibrosis, kidney damage, and pancreatic hypertrophy and reduce lipid serum levels in obese/diabetic mice models, decreasing hepatic fibrosis and portal pressure in a nonalcoholic steatohepatitis rat model [37-39]. These antecedents demonstrate the importance of FXR on corporal function via homeostasis of BA, carbohydrates, and lipids.

3.2. TGR5. The primary membrane receptor for $\mathrm{BA}$ is the G-protein-coupled TGR5, also called BG37, GPBAR1, or M-BAR. There is a correlation between BA's hydrophobicity and affinity for TGR5. Besides, the TGR5 activity associates with elevated intracellular calcium levels and cytosolic cyclic adenosine monophosphate (cAMP), independently of FXR activation $[40,41]$.
TGR5 couples mainly with G(s) protein in several tissues [42-46]. However, paradoxical effects were observed in subtypes of cholangiocytes. In ciliary cholangiocytes, TGR5 agonists diminish cAMP levels and induce the extracellular signal-regulated kinase (ERK) signaling pathway. Still, in nonciliary cholangiocytes, TGR5 activation increased the cAMP levels and inhibited the ERK pathway, subsequently activating proliferation [42, 47]. Also, TGR5 activation has been associated with the induction of other signaling pathways, such as AKT/mTOR and NF- $\kappa \mathrm{B}$ [48-50].

The metabolic effects are associated with TGR5 activation. In the gastrointestinal tract, TGR5 activation induces the expression of glucagon-like peptide-1, mediating glucose homeostasis and the BA prokinetic effect [51, 52]. Besides, TGR5 activation increases the energy expenditure in brown adipose tissue by a mechanism dependent on type 2 iodothyronine deiodinase $[43,53]$.

Recently, our group demonstrated that DCA and CA, in a TGR5-dependent manner, induced sarcopenia and atrophy in skeletal muscle by incrementing the ubiquitinproteasome system (UPS) and oxidative stress [44]. Also, the absence of the TGR5 receptor prevents the sarcopenia induced by cholestatic chronic liver disease, protecting the muscle from loss of mass and strength [54]. These results contradict a report indicating that TGR5 enhances muscle differentiation in the $\mathrm{C} 2 \mathrm{C} 12$ myoblast and induces hypertrophy in mice [45]. These studies differ in the knock-out mice model and the used BA, suggesting that more analyses are necessary to understand the effect of BA in skeletal muscle and the importance of conjugation- and hydrophobicityspecific effect.

3.3. Other Bile Acid Receptors. The sphingosine-1-phosphate receptor 2 (S1PR2) senses the phosphorylated sphingosine and mediates mainly cell proliferation and differentiation. This membrane receptor has a high affinity to conjugated BA $[55,56]$. S1PR2 activation induces the phosphorylation of ERK1/2 and AKT and reduces the BA-induced apoptosis in hepatocytes by preventing intracellular calcium oscillations [56, 57]. S1PR2 also activates the NF- $\kappa$ B pathway through EGFR/ERK1/2/AKT, inducing a proinflammatory 
response $[58,59]$. Besides, the absence of S1PR2 favors the development of fatty liver during a high-fat diet in mice through the sphingosine kinase 2 [60]. These antecedents suggest that BA may modulate lipid metabolism in the liver through S1PR2.

The pregnane $\mathrm{X}$ receptor (PXR) and constitutive androstane receptor (CAR) are intracellular sensors that mediate the detoxification process of xenobiotics [61, 62]. These receptors can bind $\mathrm{BA}$ and modulate the expression of genes involved in BA metabolism [63]. In this way, BA activates PXR and CAR, increasing the expression of enzymes (e.g., CYP3A, CYP2B, and sulfotransferases) that modify BA, reducing their hydrophobicity to decrease their toxicity. Besides, PXR and CAR generate diverse isoforms of BA's efflux transporters (MRP and OATP), increasing the clearance of hydrophobic BA [61, 64-66]. Therefore, both receptors complement the function of FXR by decreasing the toxicity and increasing the excretion of BA to protect the tissues from citotoxicity.

Also, the vitamin D receptor (VDR) can sense the LCA and its metabolites, but not other BA. Furthermore, VDR induces the expression of CYP3A on the small intestine and MRP3 in the colon $[67,68]$. These reports suggested that VDR is a sensor that mediates the protection of the intestinal tract from toxic LCA levels.

To summarize, membrane receptors, such as TGR5 and S1PR2, are mainly associated with BA-dependent endocrine/metabolic functions in diverse tissues, unlike nuclear receptors directly related to $\mathrm{BA}$ homeostasis.

\section{Bile Acid Cytotoxicity}

The lipophilicity of BA is directly proportional to their cytotoxic effect due to their potential to solubilize and disrupt cell membranes. Cellular swelling, apoptosis, alterations in membrane integrity, and release of several cellular components are characteristic of BA-induced toxicity $[9,74-76]$. In addition, due to the general structure, BA could induce lipid peroxidation and alterations in the lipid composition of membranes [77, 78].

In addition to membrane alterations, hydrophobic BA induce a proinflammatory response in hepatocytes by increasing membrane adhesion molecules and chemokines $[79,80]$. Also, CDA and its conjugated derivatives can activate the caspase pathway in a Fas receptor-dependent mechanism [81, 82]. These antecedents indicate that BA can induce a proinflammatory response and facilitate cell death (Figure 1).

The mitochondrial function is severely affected by elevated BA levels $[9,83]$. Lipophilic BA decrease the state 3 respiration and the membrane potential in mitochondria from the liver and the heart $[74,77,84]$. BA also induce the permeability transition pore and favor the release of cytochrome $\mathrm{C}$ into the cytosol, associated with the enhanced expression and translocation of $\mathrm{Bax}$ to mitochondria together with the decreased $\mathrm{Bcl}-2$ expression [83, 85-88]. Furthermore, most hydrophobic BA increase mitochondrial hydroperoxide and the accumulation of compounds derived from lipid peroxidation [89]. Nevertheless, a recent report suggests that mitochondrial toxicity does not precede cytotoxicity. Other mechanisms such as lipid membrane disruption or ROS generation explain BA-dependent cytotoxicity [9]. These antecedents suggest that mitochondria are a primary target affected by BA and can be a source of oxidative stress through alterations in the electron-transport chain, favoring the cytotoxic effect (Figure 1).

It has been widely described that increased levels of lipophilic BA can induce apoptosis in diverse cell lines and tissues. However, not all BA are associated with cell damage $[69,74,76,90]$. Particularly UDCA, the more hydrophilic $\mathrm{BA}$, prevents hepatic damage by inhibiting the JNK signaling pathway and controlling the location of proapoptotic protein Bax at the mitochondrial membrane $[75,91]$. Moreover, UDCA prevents the apoptosis induced by other molecules such as ethanol, TGF- $\beta 1$, or Fas ligand, avoiding mitochondrial dysfunction and releasing cytochrome $C$ [74, 92]. Nevertheless, coincubation of UDCA and CDCA shifts apoptosis to necrosis as the predominant cell death route in cultured human hepatocytes [83]. Similarly, the taurineconjugated UDCA reduces the DNA fragmentation and mitochondrial dysfunction induced by ischemia in rat brains and inhibits mitochondrial efflux of cytochrome $\mathrm{C}$ through PI3K signaling pathway activation in rat cortical neurons [93, 94]. Also, tauro-UDCA reduces apoptosis by preventing the increase of caspase- $12 / \mathrm{Bax}$ and the endoplasmic reticulum stress via AKT activation in mice with brain injury $[95,96]$.

In summary, BA can alter membranes, affecting cell structures, such as membrane and mitochondria. Besides, BA induce oxidative stress and proinflammatory response and also activate cell death pathways (Figure 1). All these mechanisms are closely associated with the structural properties of BA and have been used to explain their cytotoxicity.

\section{Redox-Dependent Mechanisms Participate in Damage Induced by Bile Acids}

The intracellular milieu is in a constant equilibrium between production and degradation of reactive oxygen, nitrogen, iron, copper, and sulfur species, generally named ROS [97]. A balanced ROS production is fundamental to normal cell function $[98,99]$. ROS can be divided into radical (superoxide anion or hydroxyl radical) and nonradical species (hydrogen peroxide or hypochlorous acid, among others). ROS can be generated through enzymatic or nonenzymatic reactions $[100,101]$. The intracellular oxidant species can be counterbalanced by systems that neutralize the electrophilic properties of ROS. These systems include catalase, glutathione-S-transferase, superoxide dismutase (SOD), and nonenzymatic molecules such as glutathione, thioredoxin, or vitamin E [102, 103].

Oxidative stress is established by a disturbance between ROS and antioxidants that results in excessive oxidant milieu, leading to cellular injury [97]. Oxidative stress damages cell structures by modifying proteins, lipids, nucleotides, and membranes, affecting their functions and limiting cell viability $[102,104]$. To characterize and quantify oxidative stress, the ROS levels and antioxidant activity are 


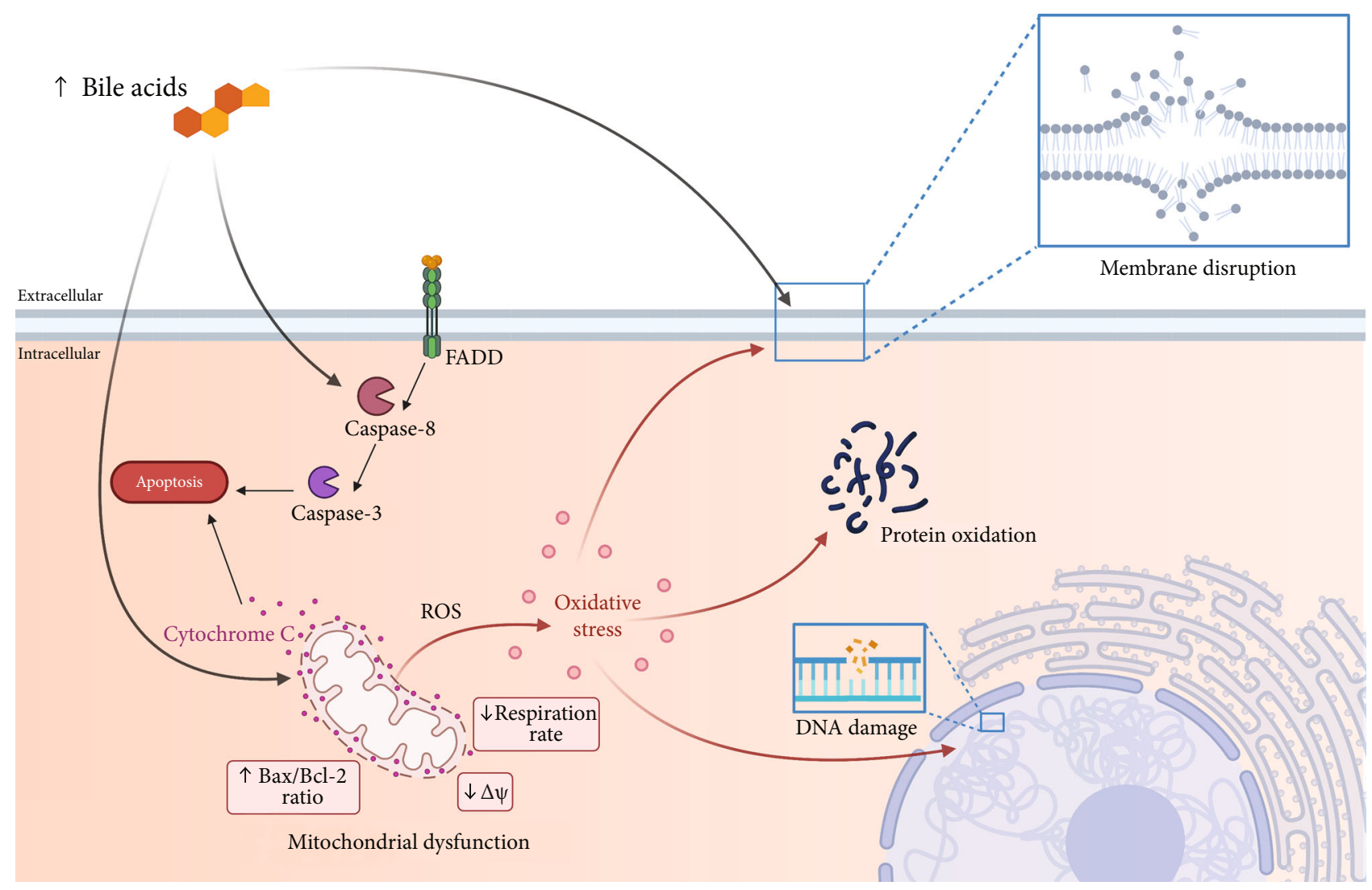

Figure 1: Cytotoxicity mechanisms induced by bile acids (BA). BA can induce membrane disruption by an alteration of stability and composition due to their steroid structure. Moreover, BA activate the caspase pathway in a Fas receptor-dependent mechanism (FADD), triggering cellular apoptosis. In addition, BA affect the mitochondrial function by (1) decreasing the rate of respiration, (2) diminishing the membrane potential, (3) increasing the permeability transition pore facilitating the translocation of cytochrome $\mathrm{C}$ and contributing to apoptosis, and (4) inducing reactive oxygen species (ROS) generation. The increased ROS levels lead to cellular oxidative stress capable of inducing DNA damage, protein oxidation, and lipid peroxidation, contributing to cellular membrane damage. All these mechanisms impair cellular viability.

typically determined. In addition, other parameters are end products of the oxidative modification such as lipid peroxidation (malondialdehyde (MDA), thiobarbituric acid-reactive substances (TBARS), 4-hydroxy-2-nonenal (4-HNE) or F2-isoprostanes), protein oxidation (carbonylated proteins), or even DNA oxidation (8-hydroxy-2' -deoxyguanosine (8OHdG)) [103].

Below, we will detail the main effects of oxidative stress in the tissues most affected by cholestatic disorders (Figure 2).

5.1. Liver. Hepatocytes are highly affected by elevated BA levels [80]. Experiments in hepatocytes showed that lipophilic BA (CDCA, DCA, and CA) increase cellular hydroperoxide, superoxide anion, and TBARS production [74, 75, 89]. Also, the taurine conjugates of CDCA and CA increase the MDA levels and correlate with a decline in hepatocyte viability. This cellular toxicity was prevented by different antioxidant mechanisms [105]. These antecedents suggest that BA-induced oxidative stress affects hepatocyte viability.

FXR regulates BA homeostasis through diverse mechanisms, explaining the predominant role on cholestasis etiology $[8,26,106]$. In this line, the absence or inhibition of FXR results in a high BA concentration in serum and promotes hepatic injury [3, 69]. The Fxr-null mice showed an increased hepatic BA concentration causing an elevation of oxidative markers such as $8-\mathrm{OHdG}$, hydroperoxide, and TBARS. Besides, these mice also increased protective Nrf2 signaling in hepatic tissue, probably to counterbalance the cellular damage [33].

Other reports using a rat model fed with a BAsupplemented diet or a bile duct ligation model showed swollen mitochondrial and impaired cellular respiration, both associated with elevated ROS production [74, 75]. Together, these results suggest that high serum concentrations of BA induce hepatic oxidative stress.

5.2. Skeletal Muscle. Extrahepatic dysfunctions characterize cholestatic hepatic diseases. Among them are weakness and skeletal muscle wasting. This complex syndrome is named sarcopenia. Among the features of sarcopenia is the decreased cross-sectional area of muscle fibers due to several molecular mechanisms such as diminished protein synthesis, high protein degradation, mitochondrial dysfunction, dysregulated autophagy, and oxidative stress [104, 107, 108]. 


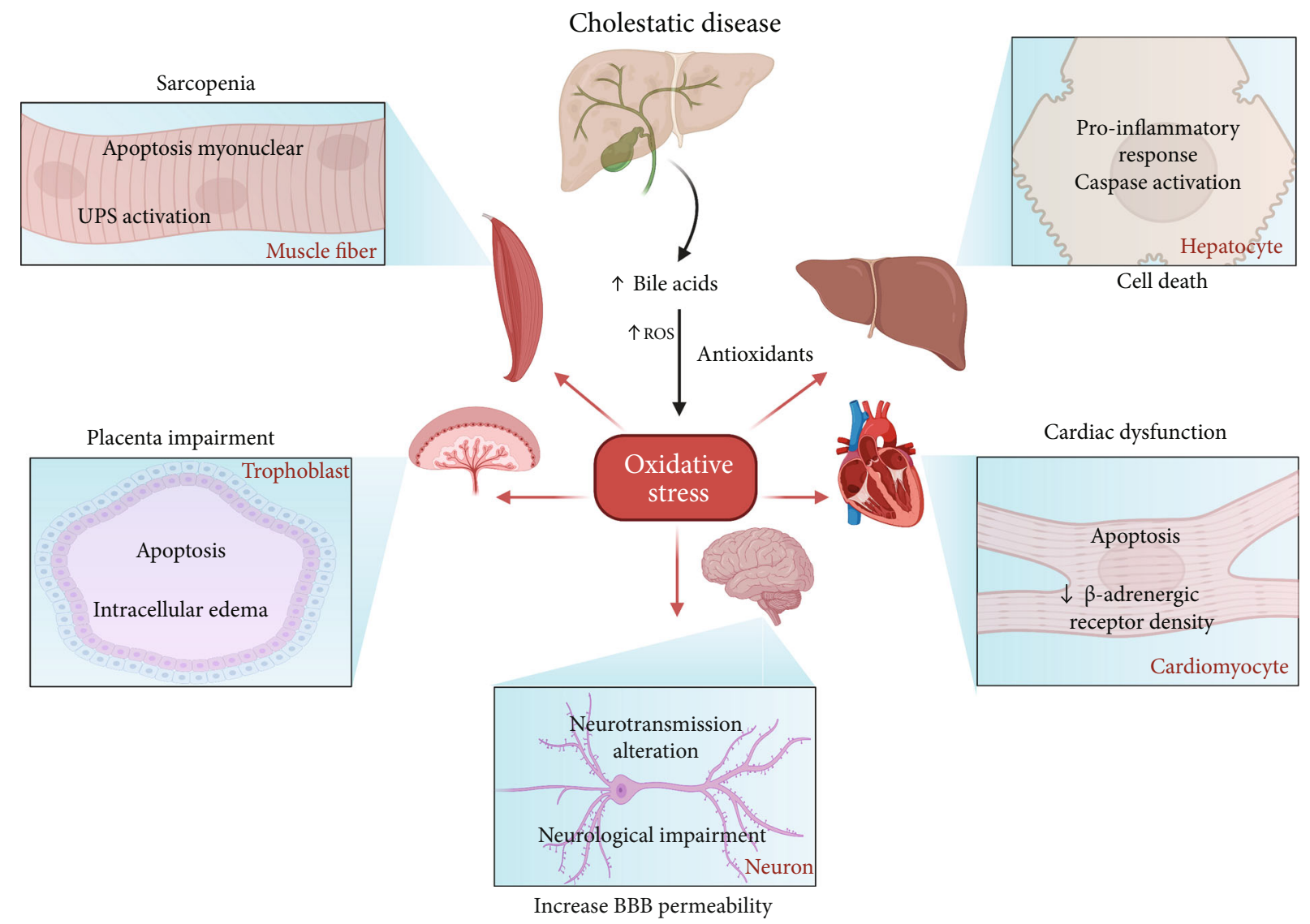

Figure 2: The effect of bile acid-induced oxidative stress in different tissues during a cholestatic disease. Cholestatic conditions provoke elevated serum levels of BA. Consequently, there is an imbalance between reactive oxygen species (ROS) and antioxidant systems, leading to oxidative stress. In skeletal muscle, sarcopenia is caused due to ubiquitin-proteasome system (UPS) activation and myonuclear apoptosis in fibers. In hepatic tissue, oxidative stress mediated a proinflammatory induction and caspase activation in hepatocytes. Besides, oxidative stress induces apoptosis and intracellular edema in the trophoblast during pregnancy, causing impairment in the placenta. Elevated BA levels increase the blood-brain barrier (BBB) permeability and correlated with neurological impairment and altered neurotransmission. Finally, oxidative stress induces cardiac dysfunction through apoptosis and a reduction in $\beta$-adrenergic receptor density in cardiomyocytes.

Our laboratory described the induction of sarcopenia in a mice model of cholestatic liver disease characterized by TGR5-dependent mechanisms: (1) oxidative stress, presenting elevated ROS, carbonylated proteins, and 4-HNE in skeletal muscles; (2) increased myonuclear apoptosis, with induction of the caspase pathway and increased Bax/Bcl-2 ratio; and (3) induction of protein catabolism through UPS $[54,107,109]$. Interestingly, ROS is directly associated with the UPS induction and mitochondrial alterations that might induce apoptosis $[108,110-112]$. In addition, the use of an antioxidant treatment ( $\mathrm{N}$-acetyl cysteine) prevents muscle damage and diminishes the apoptotic effect [109].

Moreover, recently it has been described that $\mathrm{CA}$ and DCA resemble the skeletal muscle atrophy induced by cholestatic liver disease, UPS induction, and oxidative stress. Also, the absence of TGR5 in muscle fibers abolished all harmful effects caused by these BA [44]. Thus, all these antecedents firmly suggest that elevated BA in cholestatic disorders induce oxidative stress through the TGR5 receptor, activating several intracellular events that cause sarcopenia.
A recent study has shown a relationship between muscle-BA-gut microbiota. Results indicate that the alteration of gut microbiota induced sarcopenia. This muscle dysfunction was associated with an altered profile of BA that reaches the portal blood circulation. This change induces the inhibition of ileal FXR signaling with the consequent decrease in serum levels of FGF15, an enterokine related to muscle wasting [113]. Considering the antecedents related to muscular TGR5, BA, and sarcopenia $[44,54]$, it is impossible to discard this receptor's participation in the muscle dysfunction associated with alteration in the microbiotaBA axis.

5.3. Central Nervous System. Oxidative stress is crucial in hepatic encephalopathy, and altered BA levels (elevated, changes on conjugated/unconjugated and primary/secondary ratio) could be associated with neurological decline [104, 114-116]. It was described that BA, via Racl activity, increase the blood-brain barrier permeability, facilitating the neurological changes associated with cholestatic diseases 
[116]. Also, patients with Alzheimer's disease present with increased secondary and conjugated BA levels that correlate with the disease's advanced stages [117]. Furthermore, CA, DCA, and CDCA modulate the respiratory-related rhythmic discharge activity in an FXR-dependent manner, which interferes with NMDA or GABA neurotransmission, suggesting that BA affects the brain's normal function $[118,119]$.

The FXR and TGR5 receptors have been associated with neurological damage. Downregulation of FXR in the frontal cortex replicated the neuroprotective effect of reducing BA levels in mice with acute liver failure, suggesting that FXR signaling mediates the neurological decline in this model [114]. Additionally, the absence of FXR correlates with reduced brain infarct volume, prevents neuronal apoptosis by an anti-inflammatory response, and reduces calcium influx after oxygen-glucose deprivation in a cerebral ischemia mice model [120]. Further, the TGR5 receptor in astrocytes responds to neurosteroids, molecules with structural similarities with $\mathrm{BA}$, elevating the intracellular calcium and ROS [10]. Those results confirm that the BA receptors could be relevant in generating oxidative stress and neurological impairment.

Nevertheless, tauro-UDCA prevents lipopolysaccharide depressive-like mice model, an effect that correlated with neuroinflammatory protection and decreased MDA/nitrite levels in the hippocampus and prefrontal cortex [121]. Similarly, the hydrophobic CA induced anti-inflammatory properties and reduced oxidative stress (decreasing MDA, NO, Il- $1 \beta$, and TNF- $\alpha$ ) in an integrative functional unit composed of neurons and neural supporting cells known as the neurovascular unit [12]. The prevention of oxidative stress and neuroprotective effect might be related to the TGR5 receptor. Its activation with a semisynthetic agonist decreased oxidative stress and neuronal apoptosis and downregulated the NF- $\kappa$ B pathway in mice with brain injury $[37,71]$. Those results suggest that BA might have different roles in the oxidative stress induction in CNS in noncholestatic conditions.

Considering oxidative stress with neurological pathologies and the conflicting description of $\mathrm{BA}$ on the oxidative stress in CNS, it is crucial to perform more mechanistic analysis to understand BA's role. Also, understanding the BA-CNS relation raises the possibility of proposing novel pharmacological strategies, including BA receptor modulation, for neurological disorders and neurodegenerative pathologies.

5.4. Heart. During cholestatic diseases, serum BA elevation is associated with direct toxic effects on the heart and the impairment of myocardial function [35, 90, 122]. In addition, CDCA induces apoptosis in neonatal rat ventricular myocytes due to the loss of mitochondrial membrane potential and cytochrome $\mathrm{C}$ release, as well as consequent caspasepathway activation. The bile duct ligation model resembles the cardiac proapoptotic response and shows an impairment contractibility $[82,87]$.

Also, CA decreases the heart rate and myocardial contraction and increases the markers of cardiac injury concomitantly with decreased $\beta$-adrenergic receptor density. These characteristics resemble the cardiac alteration in the FXR knock-out model and cholestatic liver disease [35, 123]. Interestingly, FXR inhibition suppresses cardiac apoptosis. Additionally, FXR inhibition in an ischemia-reperfusion model reduces cardiotoxicity and decreases myocardial infarct size improving cardiac function [87]. However, a contradictory report showed that FXR agonists activate the Nrf2 signaling (decreasing ROS, MDA, and 8-OHdG through elevated catalase, glutathione-S-transferase, and SOD), preventing cardiomyopathy in a diabetic mice model [124]. Those results suggest that BA directly and via oxidative stress could mediate the cardiotoxicity. However, the protective effect of FXR must be analyzed deeply.

Furthermore, BA also activate TGR5 in ventricular myocyte cell culture [46]. Selective TGR5 agonist (INT-777) prevents NF- $\kappa$ B activation and decreases the ROS level induced by high glucose treatment in primary cardiomyocytes [125]. Moreover, LCA prevents high glucose-induced hypertrophy in the cardiac myoblast cell line, and TGR5 upregulation alleviates the oxidative stress and inflammatory process through activating the AKT pathway in the cardiac myoblast cell line [126-128]. Also, the TGR5-dependent protective effect induced by BA in vivo was described with the administration of DCA in a cardiac injury mice model, improving cardiac remodeling and inhibiting the proinflammatory response [128]. These results suggest that TGR5 has a protective role in myocardial tissue associated with diminishing oxidative stress.

In general, BA can exert opposing effects on the myocardial tissue depending on the mediated receptor involved. All those results indicate that $\mathrm{BA}$ can be one of the responsible causes of cardiac impairment by several mechanisms in cholestasis. However, TGR5 showed a promissory pharmacological target.

5.5. Placenta. Intrahepatic cholestasis in pregnancy increases the risk of adverse outcomes, even causing intrauterine death [69]. The placenta has a protective role to the fetus from molecules of different structural nature. During pregnancy, the increased serum BA impaired the protective function of the placenta and enhanced the toxicity to the fetus $[86,129]$. Studies using trophoblast cell lines and diverse gestational cholestatic animal models showed edema and apoptosis in the placenta, attenuating with FXR agonist or UDCA treatments [69, 86, 130, 131]. Also, UDCA has been successfully proved in intrahepatic cholestasis in pregnancy patients without interfering with the placental hormone production and with no-fetal side effects. However, it does not enhance the perinatal death ratio, $\mathrm{BA}$ concentration, and itch score [132-134].

The elevated BA levels are associated with the increase of oxidative stress markers (MDA and carbonylation proteins) in the placenta, as well as the decrease of antioxidant gene expression and activity of catalase, glutathione-S-transferase, SOD, peroxiredoxin (PRDX), among others [69, 86]. Also, increased MDA levels and diminished expression of PRDX1 and PRDX3 were reported in the placenta from intrahepatic cholestasis of pregnant human patients [69]. These results suggest that oxidative stress induced by BA mediates the 
placenta's impairment and contributes to the affectation in the mother and fetus.

\section{Clinical Perspective and Conclusions}

BA are amphiphilic molecules mainly characterized by their ability to form micelles, and they are associated with nutrient absorption at the intestinal level. However, BA have endocrine functions that regulate metabolic activity and cellular energy through facilitating lipid- and carbohydrate metabolism. Several receptors are associated with BAdependent actions, such as FXR, TGR5, S1PR2, PXR, CAR, and VDR. Indeed, FXR and TGR5 have been widely studied to understand BA effects and propose novel therapeutics for cholestatic disorders.

The FXR receptor has a central role in BA physiology and carbohydrate and lipid homeostasis. Most cholestatic disorders are characterized by BA transport impairments associated with FXR malfunction, making this receptor an attractive molecular target to treat cholestasis [1, 32, 135]. Also, it has been reported that UDCA decreased FXR activation and increased triglycerides in obese patients [136]. This evidence enhances the interest in developing FXR activators. Interestingly, some non-BA molecules that can activate FXR have been tested in preclinical studies [137-140].

Conversely, the TGR5 receptor has a pivotal role in cell differentiation in some cell lines, and its activation is also associated with diverse signaling pathways $[42,48]$. Also, TGR5 activation was associated with upregulation of type 2 iodothyronine deiodinase, increased production of glucagon-like peptide- 1 , and even intestinal motility [43, 52, 141, 142]. Since the TGR5 functions are related to metabolism and there exists the need for treating metabolic diseases such as diabetes or obesity, there is an increased interest in finding novel TGR5 agonists [5, 143-145].

Due to the relevance on metabolism and gastrointestinal physiology, BA receptors have been studied as a pharmacological target to treat some diseases. Indeed, some BA such as UDCA, CA, DCA, and CDCA, have been clinically approved by the U.S. Food and Drug Administration (FDA) to treat some pathological conditions. For example, they can dissolve and prevent gallstone (UDCA), primary biliary cirrhosis (UDCA, CDCA, and obeticholic acid), BA synthesis disorders (CA), and more recently, they have been used to improve the appearance of submental fat (DCA) [146, 147].

Despite these antecedents, BA or modified BA are still under clinical research to approve their therapeutic indication. The potential use of $\mathrm{BA}$ as a treatment for pathologies has been established in phase I clinical trials. Thus, TUDCA and CDCA administration improves insulin sensitivity through increased glucagon-like peptide-1 secretion in patients with obesity and diabetes. Besides, UDCA administration induces hepatic-protective properties after radiation [148-151]. A combination of taurine-UDCA and phenylbutyrate demonstrated prevention of functional decline and prolonged survival in patients with amyotrophic lateral sclerosis $[152,153]$. Together, these clinical studies suggest that BA have promising effects on nongallbladder pathologies.
Nevertheless, more advanced clinical trials are needed to demonstrate that BA can be used in these conditions and the eventual relationship with oxidative stress.

Treatment with BA generates unwanted side effects such as diarrhea/excessive flatus and pruritus. Interestingly, modified BA and non-BA FXR agonists are helpful to prevent those adverse effects. The diarrhea is associated with alteration in secretion and motility in the colon, and activation of FXR by obeticholic acid or tropifexor (non-BA FXR agonist) increases the feedback inhibition via fibroblast growth factor 19, improving diarrhea scores [154, 155].

Although several clinical trials with BA failed to improve nonalcoholic steatohepatitis, the obeticholic acid improved hepatic histology, decreased fibrosis, and increased insulin sensitivity [156-158]. Also, obeticholic acid reduced serum alkaline phosphatase level in patients with primary biliary cholangitis [159]. However, similar to other BA, obeticholic acid developed pruritus in patients in different clinical trials $[156,159,160]$. The beneficial effect without this secondary effect was obtained by using 24-nor-UDCA in patients with primary sclerosing cholangitis or nonalcoholic fatty liver disease $[157,161]$. These reports suggest that modified BA could be the better option for future treatments. However, long-term studies with modified BA are needed to analyze the relevance of side-effect prevention, as well as the relation with oxidative stress.

Furthermore, the agonism of TGR5 or FXR could be inappropriate in other tissues, mainly in the skeletal muscle, heart, and gallbladder, presenting some adverse effects [162-164]. Recently, it has been reported that obeticholic acid may increase the gallstone risk by a mechanism dependent on FXR activation and FGF19 participation [165]. However, it is essential considering the severe side effects, mainly with long-term and high-dose BA treatments, as UDCA was associated with increased risks of developing colorectal neoplasia in primary sclerosing cholangitis, and its withdrawal deteriorates liver serum markers and increases pruritus [166-168].

More recently, there is an interest in developing FXR/TGR5 dual agonists due to an eventual synergistic effect [169]. Some beneficial effects have been reported in preclinical studies of kidney disease and liver steatosis through anti-inflammatory mechanisms [170-173]. However, there are only initial reports, and additional research is necessary to establish the relevance of this dual strategy.

The cellular alterations induced by elevated BA levels include membrane damage, proinflammatory response, mitochondrial dysfunction, and cell death by apoptosis or necrosis. All of these effects are directly or indirectly related to redoxdependent mechanisms. Interestingly, in hepatic tissues, oxidative stress and cellular damage are closely associated with FXR signaling. Meanwhile, in skeletal muscle, BA-induced injury is a TGR5-dependent process. In all mentioned tissues in this review (hepatic, skeletal muscle, CNS, heart, and placenta), oxidative stress has a significant role in apoptosis. However, an evidence gap indicates that additional research must be performed to understand and establish the complex signaling involved in the potential harm of the BA-oxidative stress axis and the long-term effect of BA as a therapeutical 
option. In the same direction, BA-induced redox signaling is a central hallmark that could be considered a target for developing innovative therapeutic options to treat cholestatic diseases.

\section{Abbreviations}

4-HNE: 4-Hydroxy-2-nonenal

8-OHdG: 8-Hydroxy-2' -deoxyguanosine

AKT: $\quad$ Protein kinase $\mathrm{B}$

BA: $\quad$ Bile acids

Bax: Bcl-2-associated X

Bcl-2: B-cell lymphoma 2

BSEP: Bile salt export pump

CA: Cholic acid

cAMP: Cyclic adenosine monophosphate

CAR: Constitutive androstane receptor

CDCA: Chenodeoxycholic acid

CNS: Central nervous system

CYP: Cytochrome

DCA: Deoxycholic acid

DNA: Deoxyribonucleic acid

EGFR: Epidermal growth factor receptor

ERK: $\quad$ Extracellular signal-regulated kinases

FXR: $\quad$ Farnesoid X receptor

LCA: Lithocholic acid

LPS: Lipopolysaccharide

MDA: Malondialdehyde

MRP: $\quad$ Multidrug resistance proteins

mTOR: Mammalian target of rapamycin

NF- $\kappa$ B: $\quad$ Nuclear factor kappa beta

OATP: Organic anion transporting polypeptide

OST: Organic solute transporter

PRDX: Peroxiredoxin

PXR: $\quad$ Pregnane X receptor

ROS: $\quad$ Reactive oxygen species

S1PR2: Sphingosine-1-phosphate receptor2

SLC: $\quad$ Solute carrier

SOD: $\quad$ Superoxide dismutase

TBARS: Thiobarbituric acid-reactive substances

TGF- $\beta 1$ : Transforming growth factor-beta type 1

TGR5: $\quad$ Takeda-G-protein-receptor-5

UDCA: Ursodeoxycholic acid

UPS: Ubiquitin-proteasome system

VDR: Vitamin D receptor.

\section{Data Availability}

Data is available on request.

\section{Conflicts of Interest}

The authors declare that they have no conflict of interest.

\section{Acknowledgments}

The manuscript was supported by research grants from the National Fund for Science and Technological Development (FONDECYT 1200944 (CCV) and 1201039 (FS)), the
Millennium Institute on Immunology and Immunotherapy (P09-016-F (CCV, FS)), and the Basal Grant CEDENNA (AFB180001 (CCV)). The Millennium Nucleus of Ion Channel-Associated Diseases (MiNICAD) is supported by the Iniciativa Científica Milenio, ANID, Chile. The online tool Biorender was used to elaborate the illustrations for this manuscript.

\section{References}

[1] S. Fiorucci and E. Distrutti, "The pharmacology of bile acids and their receptors," in Bile Acids and Their Receptors, S. Fiorucci and E. Distrutti, Eds., pp. 3-18, Springer, Cham, 2019.

[2] P. L. M. Jansen, "New therapies target the toxic consequences of cholestatic liver disease," Expert Review of Gastroenterology \& Hepatology, vol. 12, no. 3, pp. 277-285, 2018.

[3] D. A. Hollman, A. Milona, K. J. van Erpecum, and S. W. van Mil, "Anti-inflammatory and metabolic actions of FXR: insights into molecular mechanisms," Biochimica et Biophysica Acta, vol. 1821, no. 11, pp. 1443-1452, 2012.

[4] N. I. Hanafi, A. S. Mohamed, S. H. S. A. Kadir, and M. H. D. Othman, "Overview of bile acids signaling and perspective on the signal of ursodeoxycholic acid, the most hydrophilic bile acid, in the heart," Biomolecules, vol. 8, no. 4, 2018.

[5] P. Santiago, A. R. Scheinberg, and C. Levy, "Cholestatic liver diseases: new targets, new therapies," Therapeutic Advances in Gastroenterology, vol. 11, 2018.

[6] R. Yokoda and E. Rodriguez, "Review: Pathogenesis of cholestatic liver diseases," World Journal of Hepatology, vol. 12, no. 8, pp. 423-435, 2020.

[7] A. Perino, H. Demagny, L. Velazquez-Villegas, and K. Schoonjans, "Molecular physiology of bile acid signaling in health, disease, and aging," Physiological Reviews, vol. 101, no. 2, pp. 683-731, 2021.

[8] J. Y. L. Chiang and J. M. Ferrell, "Bile acid metabolism in liver pathobiology," Gene Expression, vol. 18, no. 2, pp. 71-87, 2018.

[9] S. L. Penman, P. Sharma, H. Aerts, B. K. Park, R. J. Weaver, and A. E. Chadwick, "Differential toxic effects of bile acid mixtures in isolated mitochondria and physiologically relevant HepaRG cells," Toxicology In Vitro, vol. 61, p. 104595, 2019.

[10] V. Keitel, B. Gorg, H. J. Bidmon et al., "The bile acid receptor TGR5 (Gpbar-1) acts as a neurosteroid receptor in brain," Glia, vol. 58, no. 15, pp. 1794-1805, 2010.

[11] M. McMillin, G. Frampton, M. Quinn et al., "Bile acid signaling is involved in the neurological decline in a murine model of acute liver failure," The American Journal of Pathology, vol. 186, no. 2, pp. 312-323, 2016.

[12] C. Li, X. Wang, J. Yan et al., "Cholic acid protects in vitro neurovascular units against oxygen and glucose peprivationinduced injury through the BDNF-TrkB signaling pathway," Oxidative Medicine and Cellular Longevity, vol. 2020, Article ID 1201624, 14 pages, 2020.

[13] J. Y. Chiang, "Bile acid metabolism and signaling," Comprehensive Physiology, vol. 3, no. 3, pp. 1191-1212, 2013.

[14] A. Di Ciaula, G. Garruti, R. Lunardi Baccetto et al., "Bile acid physiology," Annals of Hepatology, vol. 16, pp. S4S14, 2017. 
[15] J. M. Ridlon, D. J. Kang, and P. B. Hylemon, "Bile salt biotransformations by human intestinal bacteria," Journal of Lipid Research, vol. 47, no. 2, pp. 241-259, 2006.

[16] J. M. Ridlon, S. C. Harris, S. Bhowmik, D. J. Kang, and P. B. Hylemon, "Consequences of bile salt biotransformations by intestinal bacteria," Gut Microbes, vol. 7, no. 1, pp. 22-39, 2016.

[17] E. D'Aldebert, M. J. B. B. Mve, M. Mergey et al., "Bile salts control the antimicrobial peptide cathelicidin through nuclear receptors in the human biliary epithelium," Gastroenterology, vol. 136, no. 4, pp. 1435-1443, 2009.

[18] J. Y. L. Chiang and J. M. Ferrell, "Bile acid receptors FXR and TGR5 signaling in fatty liver diseases and therapy," American Journal of Physiology. Gastrointestinal and Liver Physiology, vol. 318, no. 3, pp. G554-G573, 2020.

[19] D. J. Parks, S. G. Blanchard, R. K. Bledsoe et al., "Bile acids: natural ligands for an orphan nuclear receptor," Science, vol. 284, no. 5418, pp. 1365-1368, 1999.

[20] H. Wang, J. Chen, K. Hollister, L. C. Sowers, and B. M. Forman, "Endogenous bile acids are ligands for the nuclear receptor FXR/BAR,” Molecular Cell, vol. 3, no. 5, pp. 543553, 1999.

[21] M. Makishima, A. Y. Okamoto, J. J. Repa et al., "Identification of a nuclear receptor for bile acids," Science, vol. 284, no. 5418, pp. 1362-1365, 1999.

[22] Y. Zhang, H. R. Kast-Woelbern, and P. A. Edwards, "Natural Structural Variants of the Nuclear Receptor Farnesoid X Receptor Affect Transcriptional Activation," The Journal of Biological Chemistry, vol. 278, no. 1, pp. 104-110, 2003.

[23] K. Otte, H. Kranz, I. Kober et al., "Identification of farnesoid $\mathrm{X}$ receptor beta as a novel mammalian nuclear receptor sensing lanosterol," Molecular and Cellular Biology, vol. 23, no. 3, pp. 864-872, 2003.

[24] B. Goodwin, S. Jones, R. Price et al., "A regulatory cascade of the nuclear receptors FXR, SHP-1, and LRH-1 represses bile acid biosynthesis," Molecular Cell, vol. 6, no. 3, pp. 517526, 2000.

[25] M. Zhang and J. Y. Chiang, "Transcriptional Regulation of the Human Sterol 12 $\alpha$-Hydroxylase Gene (CYP8B1):," The Journal of Biological Chemistry, vol. 276, no. 45, pp. 4169041699, 2001.

[26] S. Anakk, M. Watanabe, S. A. Ochsner, N. J. McKenna, M. J. Finegold, and D. D. Moore, "Combined deletion of Fxr and Shp in mice induces Cyp17al and results in juvenile onset cholestasis," The Journal of Clinical Investigation, vol. 121, no. 1, pp. 86-95, 2011.

[27] L. A. Denson, E. Sturm, W. Echevarria et al., "The orphan nuclear receptor, shp, mediates bile acid-induced inhibition of the rat bile acid transporter, ntcp," Gastroenterology, vol. 121, no. 1, pp. 140-147, 2001.

[28] M. Ananthanarayanan, N. Balasubramanian, M. Makishima, D. J. Mangelsdorf, and F. J. Suchy, "Human Bile Salt Export Pump Promoter Is Transactivated by the Farnesoid X Receptor/Bile Acid Receptor," The Journal of Biological Chemistry, vol. 276, no. 31, pp. 28857-28865, 2001.

[29] H. R. Kast, B. Goodwin, P. T. Tarr et al., "Regulation of Multidrug Resistance-associated Protein 2 (ABCC2) by the Nuclear Receptors Pregnane X Receptor, Farnesoid Xactivated Receptor, and Constitutive Androstane Receptor," The Journal of Biological Chemistry, vol. 277, no. 4, pp. 2908-2915, 2002.
[30] J. L. Boyer, M. Trauner, A. Mennone et al., "Upregulation of a basolateral FXR-dependent bile acid efflux transporter OSTalpha-OSTbeta in cholestasis in humans and rodents," American Journal of Physiology. Gastrointestinal and Liver Physiology, vol. 290, no. 6, pp. G1124-G1130, 2006.

[31] F. Chen, L. Ma, P. A. Dawson et al., "Liver Receptor Homologue-1 Mediates Species- and Cell Line-specific Bile Acid- dependent Negative Feedback Regulation of the Apical Sodium-dependent Bile Acid Transporter," The Journal of Biological Chemistry, vol. 278, no. 22, pp. 19909-19916, 2003.

[32] C. Sinal, M. Tohkin, M. Miyata, J. Ward, G. Lambert, and F. Gonzalez, "Targeted disruption of the nuclear receptor FXR/BAR impairs bile acid and lipid homeostasis," Cell, vol. 102, no. 6, pp. 731-744, 2000.

[33] M. Nomoto, M. Miyata, S. Yin et al., "Bile acid-induced elevated oxidative stress in the absence of farnesoid X receptor," Biological \& Pharmaceutical Bulletin, vol. 32, no. 2, pp. 172178, 2009.

[34] G. Lambert, M. J. Amar, G. Guo, H. B. Brewer Jr., F. J. Gonzalez, and C. J. Sinal, "The Farnesoid X-receptor Is an Essential Regulator of Cholesterol Homeostasis," The Journal of Biological Chemistry, vol. 278, no. 4, pp. 25632570, 2003.

[35] M. S. Desai, B. Mathur, Z. Eblimit et al., "Bile acid excess induces cardiomyopathy and metabolic dysfunctions in the heart," Hepatology, vol. 65, no. 1, pp. 189-201, 2017.

[36] S. Qiang, L. Tao, J. Zhou et al., "Knockout of farnesoid X receptor aggravates process of diabetic cardiomyopathy," Diabetes Research and Clinical Practice, vol. 161, article 108033, 2020.

[37] X. Wu, Y. G. Lv, Y. F. Du et al., "Inhibitory effect of INT-777 on lipopolysaccharide-induced cognitive impairment, neuroinflammation, apoptosis, and synaptic dysfunction in mice," Progress in Neuro-Psychopharmacology \& Biological Psychiatry, vol. 88, pp. 360-374, 2019.

[38] S. Y. Han, H. K. Song, J. J. Cha, J. Y. Han, Y. S. Kang, and D. R. Cha, "Farnesoid X receptor (FXR) agonist ameliorates systemic insulin resistance, dysregulation of lipid metabolism, and alterations of various organs in a type 2 diabetic kidney animal model," Acta Diabetologica, vol. 58, no. 4, pp. 495-503, 2021.

[39] P. Schwabl, E. Hambruch, G. R. Budas et al., "The nonsteroidal FXR agonist cilofexor improves portal hypertension and reduces hepatic fibrosis in a rat NASH model," Biomedicines, vol. 9, no. 1, p. 60, 2021.

[40] T. Maruyama, Y. Miyamoto, T. Nakamura et al., "Identification of membrane-type receptor for bile acids (M-BAR)," Biochemical and Biophysical Research Communications, vol. 298, no. 5, pp. 714-719, 2002.

[41] Y. Kawamata, R. Fujii, M. Hosoya et al., "A G Proteincoupled Receptor Responsive to Bile Acids," The Journal of Biological Chemistry, vol. 278, no. 11, pp. 9435-9440, 2003.

[42] A. I. Masyuk, B. Q. Huang, B. N. Radtke et al., "Ciliary subcellular localization of TGR5 determines the cholangiocyte functional response to bile acid signaling," American Journal of Physiology. Gastrointestinal and Liver Physiology, vol. 304, no. 11, pp. G1013-G1024, 2013.

[43] M. Watanabe, S. M. Houten, C. Mataki et al., "Bile acids induce energy expenditure by promoting intracellular thyroid hormone activation," Nature, vol. 439, no. 7075, pp. $484-489,2006$. 
[44] J. Abrigo, F. Gonzalez, F. Aguirre et al., "Cholic acid and deoxycholic acid induce skeletal muscle atrophy through a mechanism dependent on TGR5 receptor," Journal of Cellular Physiology, vol. 236, no. 1, pp. 260-272, 2021.

[45] T. Sasaki, A. Kuboyama, M. Mita et al., "The exerciseinducible bile acid receptor Tgr5 improves skeletal muscle function in mice," The Journal of Biological Chemistry, vol. 293, no. 26, pp. 10322-10332, 2018.

[46] E. Ibrahim, I. Diakonov, D. Arunthavarajah et al., "Bile acids and their respective conjugates elicit different responses in neonatal cardiomyocytes: role of $\mathrm{Gi}$ protein, muscarinic receptors and TGR5," Scientific Reports, vol. 8, no. 1, article 7110, 2018

[47] C. Guo, W. D. Chen, and Y. D. Wang, "TGR5, Not Only a Metabolic Regulator," Frontiers in Physiology, vol. 7, p. 646, 2016.

[48] Y. D. Wang, W. D. Chen, D. Yu, B. M. Forman, and W. Huang, "The G-protein-coupled bile acid receptor, Gpbar1 (TGR5), negatively regulates hepatic inflammatory response through antagonizing nuclear factor $\kappa$ light-chain enhancer of activated B cells (NF- $\kappa \mathrm{B}$ ) in mice," Hepatology, vol. 54, no. 4, pp. 1421-1432, 2011.

[49] T. Kida, Y. Tsubosaka, M. Hori, H. Ozaki, and T. Murata, "Bile acid receptor TGR5 agonism induces NO production and reduces monocyte adhesion in vascular endothelial cells," Arteriosclerosis, Thrombosis, and Vascular Biology, vol. 33, no. 7, pp. 1663-1669, 2013.

[50] A. Perino, T. W. Pols, M. Nomura, S. Stein, R. Pellicciari, and K. Schoonjans, "TGR5 reduces macrophage migration through mTOR-induced C/EBP $\beta$ differential translation," The Journal of Clinical Investigation, vol. 124, no. 12, pp. 5424-5436, 2014.

[51] F. Alemi, D. P. Poole, J. Chiu et al., "The receptor TGR5 mediates the prokinetic actions of intestinal bile acids and is required for normal defecation in mice," Gastroenterology, vol. 144, no. 1, pp. 145-154, 2013.

[52] M. J. Potthoff, A. Potts, T. He et al., "Colesevelam suppresses hepatic glycogenolysis by TGR5-mediated induction of GLP1 action in DIO mice," American Journal of Physiology. Gastrointestinal and Liver Physiology, vol. 304, no. 4, pp. G371-G380, 2013.

[53] E. P. Broeders, E. B. Nascimento, B. Havekes et al., “The bile acid chenodeoxycholic acid increases human brown adipose tissue activity," Cell Metabolism, vol. 22, no. 3, pp. 418-426, 2015.

[54] J. Abrigo, F. Campos, F. Gonzalez et al., "Sarcopenia induced by chronic liver disease in mice requires the expression of the bile acids membrane receptor TGR5," International Journal of Molecular Sciences, vol. 21, no. 21, p. 7922, 2020.

[55] M. Maceyka, K. B. Harikumar, S. Milstien, and S. Spiegel, "Sphingosine-1-phosphate signaling and its role in disease," Trends in Cell Biology, vol. 22, no. 1, pp. 50-60, 2012.

[56] E. Studer, X. Zhou, R. Zhao et al., "Conjugated bile acids activate the sphingosine-1-phosphate receptor 2 in primary rodent hepatocytes," Hepatology, vol. 55, no. 1, pp. 267-276, 2012.

[57] G. Karimian, M. Buist-Homan, M. Schmidt et al., "Sphingosine kinase-1 inhibition protects primary rat hepatocytes against bile salt-induced apoptosis," Biochimica et Biophysica Acta, vol. 1832, no. 12, pp. 1922-1929, 2013.
[58] G. Zhang, L. Yang, G. S. Kim et al., "Critical role of sphingosine-1-phosphate receptor 2 (S1PR2) in acute vascular inflammation," Blood, vol. 122, no. 3, pp. 443-455, 2013.

[59] R. Liu, X. Li, X. Qiang et al., "Bile Acid and S1PR2-mediated Signaling in CCA," The Journal of Biological Chemistry, vol. 290, no. 52, pp. 30988-31002, 2015.

[60] M. Nagahashi, K. Takabe, R. Liu et al., "Conjugated bile acidactivated S1P receptor 2 is a key regulator of sphingosine kinase 2 and hepatic gene expression," Hepatology, vol. 61, no. 4, pp. 1216-1226, 2015.

[61] J. Staudinger, B. Goodwin, S. Jones et al., "The nuclear receptor PXR is a lithocholic acid sensor that protects against liver toxicity," Proceedings of the National Academy of Sciences of the United States of America, vol. 98, no. 6, pp. 3369-3374, 2001.

[62] W. Xie, J. L. Barwick, C. M. Simon et al., "Reciprocal activation of xenobiotic response genes by nuclear receptors SXR/PXR and CAR," Genes \& Development, vol. 14, no. 23, pp. 3014-3023, 2000.

[63] D. J. Shin and L. Wang, "Bile acid-activated receptors: a review on FXR and other nuclear receptors," Handbook of Experimental Pharmacology, vol. 256, pp. 51-72, 2019.

[64] W. Xie, A. Radominska-Pandya, Y. Shi et al., "An essential role for nuclear receptors SXR/PXR in detoxification of cholestatic bile acids," Proceedings of the National Academy of Sciences of the United States of America, vol. 98, no. 6, pp. 3375-3380, 2001.

[65] M. Wagner, E. Halilbasic, H. U. Marschall et al., "CAR and PXR agonists stimulate hepatic bile acid and bilirubin detoxification and elimination pathways in mice," Hepatology, vol. 42, no. 2, pp. 420-430, 2005.

[66] C. Stedman, C. Liddle, S. Coulter et al., "Nuclear receptors constitutive androstane receptor and pregnane $\mathrm{X}$ receptor ameliorate cholestatic liver injury," Proceedings of the National Academy of Sciences of the United States of America, vol. 102, no. 6, pp. 2063-2068, 2005.

[67] M. Makishima, T. Lu, W. Xie et al., "Vitamin D receptor as an intestinal bile acid sensor," Science, vol. 296, no. 5571, pp. 1313-1316, 2002.

[68] T. C. McCarthy, X. Li, and C. J. Sinal, "Vitamin D Receptordependent Regulation of Colon Multidrug Resistance- associated Protein 3 Gene Expression by Bile Acids," The Journal of Biological Chemistry, vol. 280, no. 24, pp. 23232-23242, 2005.

[69] W. B. Wu, Y. Y. Xu, W. W. Cheng et al., "Agonist of farnesoid $X$ receptor protects against bile acid induced damage and oxidative stress in mouse placenta - A study on maternal cholestasis model," Placenta, vol. 36, no. 5, pp. 545-551, 2015.

[70] A. L. Bookout, Y. Jeong, M. Downes, R. T. Yu, R. M. Evans, and D. J. Mangelsdorf, "Anatomical profiling of nuclear receptor expression reveals a hierarchical transcriptional network," Cell, vol. 126, no. 4, pp. 789-799, 2006.

[71] G. Zuo, T. Zhang, L. Huang et al., "Activation of TGR5 with INT-777 attenuates oxidative stress and neuronal apoptosis via $\mathrm{CAMP/PKC \varepsilon /ALDH} 2$ pathway after subarachnoid hemorrhage in rats," Free Radical Biology \& Medicine, vol. 143, pp. 441-453, 2019.

[72] V. Keitel, J. Stindt, and D. Haussinger, "Bile acid-activated receptors: GPBAR1 (TGR5) and other G protein-coupled receptors," in Bile Acids and Their Receptors, S. Fiorucci and E. Distrutti, Eds., pp. 19-49, Springer, Cham, 2019. 
[73] E. Kwong, Y. Li, P. B. Hylemon, and H. Zhou, "Bile acids and sphingosine-1-phosphate receptor 2 in hepatic lipid metabolism," Acta Pharmaceutica Sinica B, vol. 5, no. 2, pp. 151-157, 2015.

[74] C. M. Rodrigues, G. Fan, P. Wong, B. T. Kren, and C. J. Steer, "Ursodeoxycholic acid may inhibit deoxycholic acid-induced apoptosis by modulating mitochondrial transmembrane potential and reactive oxygen species production," Molecular Medicine, vol. 4, no. 3, pp. 165-178, 1998.

[75] C. M. Rodrigues, G. Fan, X. Ma, B. T. Kren, and C. J. Steer, “A novel role for ursodeoxycholic acid in inhibiting apoptosis by modulating mitochondrial membrane perturbation," The Journal of Clinical Investigation, vol. 101, no. 12, pp. 27902799, 1998.

[76] M. J. Perez, R. I. Macias, C. Duran, M. J. Monte, J. M. Gonzalez-Buitrago, and J. J. Marin, "Oxidative stress and apoptosis in fetal rat liver induced by maternal cholestasis. Protective effect of ursodeoxycholic acid," Journal of Hepatology, vol. 43, no. 2, pp. 324-332, 2005.

[77] S. Krahenbul, C. Talos, S. Fischer, and J. Reichen, "Toxicity of bile acids on the electron transport chain of isolated rat liver mitochondria," Hepatology, vol. 20, no. 6, pp. 1595-1601, 1994.

[78] H. Gazawi, P. Ljubuncic, U. Cogan, E. Hochgraff, D. BenShachar, and A. Bomzon, "The effects of bile acids on $\beta$-adrenoceptors, fluidity, and the extent of lipid peroxidation in rat cardiac membranes," Biochemical Pharmacology, vol. 59, no. 12, pp. 1623-1628, 2000.

[79] K. Allen, H. Jaeschke, and B. L. Copple, "Bile acids induce inflammatory genes in hepatocytes: a novel mechanism of inflammation during obstructive cholestasis," The American Journal of Pathology, vol. 178, no. 1, pp. 175-186, 2011.

[80] M. Li, S. Y. Cai, and J. L. Boyer, "Mechanisms of bile acid mediated inflammation in the liver," Molecular Aspects of Medicine, vol. 56, pp. 45-53, 2017.

[81] W. Faubion, E. Guicciardi, H. Miyoshi et al., "Toxic bile salts induce rodent hepatocyte apoptosis via direct activation of Fas," The Journal of Clinical Investigation, vol. 103, no. 1, pp. 137-145, 1999.

[82] S. W. Nam, H. Liu, J. Z. Wong et al., "Cardiomyocyte apoptosis contributes to pathogenesis of cirrhotic cardiomyopathy in bile duct-ligated mice," Clinical Science (London, England), vol. 127, no. 8, pp. 519-526, 2014.

[83] A. P. Rolo, C. M. Palmeira, J. M. Holy, and K. B. Wallace, "Role of mitochondrial dysfunction in combined bile acidinduced cytotoxicity: the switch between apoptosis and necrosis," Toxicological Sciences, vol. 79, no. 1, pp. 196-204, 2004.

[84] M. Ferreira, P. Coxito, V. Sardão, C. Palmeira, and P. Oliveira, "Bile acids are toxic for isolated cardiac mitochondria: a possible cause for hepatic-derived cardiomyopathies?," Cardiovascular Toxicology, vol. 5, no. 1, pp. 63-74, 2005.

[85] B. Yerushalmi, R. Dahl, M. W. Devereaux, E. Gumpricht, and R. J. Sokol, "Bile acid-induced rat hepatocyte apoptosis is inhibited by antioxidants and blockers of the mitochondrial permeability transition," Hepatology, vol. 33, no. 3, pp. 616626, 2001.

[86] M. J. Perez, R. I. Macias, and J. J. Marin, "Maternal cholestasis induces placental oxidative stress and apoptosis. Protective effect of ursodeoxycholic acid," Placenta, vol. 27, no. 1, pp. 34-41, 2006.
[87] J. Pu, A. Yuan, P. Shan et al., "Cardiomyocyte-expressed farnesoid-X-receptor is a novel apoptosis mediator and contributes to myocardial ischaemia/reperfusion injury," European Heart Journal, vol. 34, no. 24, pp. 1834-1845, 2013.

[88] J. Ignacio Barrasa, N. Olmo, P. Perez-Ramos et al., "Deoxycholic and chenodeoxycholic bile acids induce apoptosis via oxidative stress in human colon adenocarcinoma cells," Apoptosis, vol. 16, no. 10, pp. 1054-1067, 2011.

[89] R. Sokol, B. Winklhofer-Roob, M. Devereaux, and J. McKim Jr., "Generation of hydroperoxides in isolated rat hepatocytes and hepatic mitochondria exposed to hydrophobic bile acids," Gastroenterology, vol. 109, no. 4, pp. 1249-1256, 1995.

[90] T. Vasavan, E. Ferraro, E. Ibrahim, P. Dixon, J. Gorelik, and C. Williamson, "Heart and bile acids - Clinical consequences of altered bile acid metabolism," Biochimica et Biophysica Acta (BBA) - Molecular Basis of Disease, vol. 1864, 4, Part B, pp. 1345-1355, 2018.

[91] D. Graf, A. K. Kurz, R. Fischer, R. Reinehr, and D. Haussinger, "Taurolithocholic acid-3 sulfate induces CD95 trafficking and apoptosis in a c-Jun N-terminal kinase-dependent manner," Gastroenterology, vol. 122, no. 5, pp. 1411-1427, 2002.

[92] C. M. Rodrigues, X. Ma, C. Linehan-Stieers, G. Fan, B. T. Kren, and C. J. Steer, "Ursodeoxycholic acid prevents cytochrome $c$ release in apoptosis by inhibiting mitochondrial membrane depolarization and channel formation," Cell Death and Differentiation, vol. 6, no. 9, pp. 842-854, 1999.

[93] C. Rodrigues, S. Spellman, S. Solá et al., "Neuroprotection by a bile acid in an acute stroke model in the rat," Journal of Cerebral Blood Flow and Metabolism, vol. 22, no. 4, pp. 463-471, 2002.

[94] R. E. Castro, S. Sola, R. M. Ramalho, C. J. Steer, and C. M. Rodrigues, "The bile acid tauroursodeoxycholic acid modulates phosphorylation and translocation of bad via phosphatidylinositol 3-kinase in glutamate-induced apoptosis of rat cortical neurons," The Journal of Pharmacology and Experimental Therapeutics, vol. 311, no. 2, pp. 845-852, 2004.

[95] X. Chen, J. Wang, X. Gao et al., "Tauroursodeoxycholic acid prevents ER stress-induced apoptosis and improves cerebral and vascular function in mice subjected to subarachnoid hemorrhage," Brain Research, vol. 1727, article 146566, 2020.

[96] D. Sun, G. Gu, J. Wang et al., "Administration of tauroursodeoxycholic acid attenuates early brain injury via Akt pathway activation," Frontiers in Cellular Neuroscience, vol. 11, p. 193, 2017.

[97] B. Poljsak, D. Suput, and I. Milisav, "Achieving the balance between ROS and antioxidants: when to use the synthetic antioxidants," Oxidative Medicine and Cellular Longevity, vol. 2013, Article ID 956792, 11 pages, 2013.

[98] L. Zhang, X. Wang, R. Cueto et al., "Biochemical basis and metabolic interplay of redox regulation," Redox Biology, vol. 26, article 101284, 2019.

[99] C. R. Reczek and N. S. Chandel, "ROS-dependent signal transduction," Current Opinion in Cell Biology, vol. 33, pp. 8-13, 2015.

[100] D. Lichtenberg and I. Pinchuk, "Oxidative stress, the term and the concept," Biochemical and Biophysical Research Communications, vol. 461, no. 3, pp. 441-444, 2015.

[101] H. Sies, "Oxidative stress: a concept in redox biology and medicine," Redox Biology, vol. 4, pp. 180-183, 2015. 
[102] K. Neha, M. R. Haider, A. Pathak, and M. S. Yar, "Medicinal prospects of antioxidants: a review," European Journal of Medicinal Chemistry, vol. 178, pp. 687-704, 2019.

[103] A. Rahal, A. Kumar, V. Singh et al., "Oxidative stress, prooxidants, and antioxidants: the interplay," BioMed Research International, vol. 2014, Article ID 761264, 19 pages, 2014.

[104] A. Gonzalez, C. Huerta-Salgado, J. Orozco-Aguilar et al., "Role of oxidative stress in hepatic and extrahepatic dysfunctions during nonalcoholic fatty liver disease (NAFLD)," Oxidative Medicine and Cellular Longevity, vol. 2020, Article ID 1617805, 16 pages, 2020.

[105] R. Sokol, M. Devereaux, R. Khandwala, and K. O'Brien, "Evidence for involvement of oxygen free radicals in bile acid toxicity to isolated rat hepatocytes," Hepatology, vol. 17, no. 5, pp. 869-881, 1993.

[106] N. Gomez-Ospina, C. J. Potter, R. Xiao et al., "Mutations in the nuclear bile acid receptor FXR cause progressive familial intrahepatic cholestasis," Nature Communications, vol. 7, no. $1,2016$.

[107] F. Campos, J. Abrigo, F. Aguirre et al., "Sarcopenia in a mice model of chronic liver disease: role of the ubiquitinproteasome system and oxidative stress," Pflügers Archiv, vol. 470, no. 10, pp. 1503-1519, 2018.

[108] J. Abrigo, A. A. Elorza, C. A. Riedel et al., "Role of oxidative stress as key regulator of muscle wasting during cachexia," Oxidative Medicine and Cellular Longevity, vol. 2018, Article ID 2063179, 17 pages, 2018.

[109] J. Abrigo, T. Marin, F. Aguirre et al., "N-Acetyl cysteine attenuates the sarcopenia and muscle apoptosis induced by chronic liver disease," Current Molecular Medicine, vol. 20, no. 1, pp. 60-71, 2019.

[110] G. Dobrowolny, M. Aucello, E. Rizzuto et al., "Skeletal muscle is a primary target of SOD $1^{\mathrm{G} 93 \mathrm{~A}}$-mediated toxicity," Cell Metabolism, vol. 8, no. 5, pp. 425-436, 2008.

[111] P. M. Siu, Y. Wang, and S. E. Alway, "Apoptotic signaling induced by $\mathrm{H}_{2} \mathrm{O}_{2}$-mediated oxidative stress in differentiated C2C12 myotubes," Life Sciences, vol. 84, no. 13-14, pp. 468481, 2009.

[112] D. Bloemberg and J. Quadrilatero, “Autophagy, apoptosis, and mitochondria: molecular integration and physiological relevance in skeletal muscle," American Journal of Physiology. Cell Physiology, vol. 317, no. 1, pp. C111-C130, 2019.

[113] Y. Qiu, J. Yu, Y. Li et al., "Depletion of gut microbiota induces skeletal muscle atrophy by FXR-FGF15/19 signalling," Annals of Medicine, vol. 53, no. 1, pp. 508-522, 2021.

[114] M. McMillin and S. DeMorrow, "Effects of bile acids on neurological function and disease," The FASEB Journal, vol. 30, no. 11, pp. $3658-3668,2016$.

[115] C. R. Martin, V. Osadchiy, A. Kalani, and E. A. Mayer, "The brain-gut-microbiome axis," Cellular and Molecular Gastroenterology and Hepatology, vol. 6, no. 2, pp. 133148, 2018.

[116] M. Quinn, M. McMillin, C. Galindo, G. Frampton, H. Y. Pae, and S. DeMorrow, "Bile acids permeabilize the blood brain barrier after bile duct ligation in rats via Rac1-dependent mechanisms," Digestive and Liver Disease, vol. 46, no. 6, pp. 527-534, 2014.

[117] S. MahmoudianDehkordi, M. Arnold, K. Nho et al., "Altered bile acid profile associates with cognitive impairment in Alzheimer's disease-an emerging role for gut microbiome," Alzheimers Dement, vol. 15, no. 1, pp. 76-92, 2019.
[118] S. R. Schubring, W. Fleischer, J. S. Lin, H. L. Haas, and O. A. Sergeeva, "The bile steroid chenodeoxycholate is a potent antagonist at NMDA and $\mathrm{GABA}_{\mathrm{A}}$ receptors," Neuroscience Letters, vol. 506, no. 2, pp. 322-326, 2012.

[119] C. Zhao, X. Wang, Y. Cong et al., "Effects of bile acids and the bile acid receptor FXR agonist on the respiratory rhythm in the in vitro brainstem medulla slice of neonatal SpragueDawley rats," PLoS One, vol. 9, no. 11, article e112212, 2014.

[120] H. M. Shan, M. Zang, Q. Zhang et al., "Farnesoid X receptor knockout protects brain against ischemic injury through reducing neuronal apoptosis in mice," Journal of Neuroinflammation, vol. 17, no. 1, p. 164, 2020.

[121] L. Cheng, C. Huang, and Z. Chen, "Tauroursodeoxycholic acid ameliorates lipopolysaccharide-induced depression like behavior in mice via the inhibition of neuroinflammation and oxido-nitrosative stress," Pharmacology, vol. 103, no. 12, pp. 93-100, 2019.

[122] S. Moller, K. V. Danielsen, S. Wiese, J. D. Hove, and F. Bendtsen, "An update on cirrhotic cardiomyopathy," Expert Review of Gastroenterology \& Hepatology, vol. 13, no. 5, pp. 497-505, 2019.

[123] M. S. Desai, Z. Eblimit, S. Thevananther et al., "Cardiomyopathy reverses with recovery of liver injury, cholestasis and cholanemia in mouse model of biliary fibrosis," Liver International, vol. 35, no. 4, pp. 1464-1477, 2015.

[124] H. Wu, G. Liu, Y. He, J. Da, and B. Xie, "Obeticholic acid protects against diabetic cardiomyopathy by activation of FXR/Nrf2 signaling in db/db mice," European Journal of Pharmacology, vol. 858, article 172393, 2019.

[125] L. Deng, X. Chen, Y. Zhong et al., "Activation of TGR5 partially alleviates high glucose-induced cardiomyocyte injury by inhibition of inflammatory responses and oxidative stress," Oxidative Medicine and Cellular Longevity, vol. 2019, Article ID 6372786, 11 pages, 2019.

[126] K. C. Cheng, W. T. Chang, F. Y. Kuo, Z. C. Chen, Y. Li, and J. T. Cheng, "TGR5 activation ameliorates hyperglycemiainduced cardiac hypertrophy in $\mathrm{H} 9 \mathrm{c} 2$ cells," Scientific Reports, vol. 9, no. 1, article 3633, 2019.

[127] J. Li, R. Cheng, and H. Wan, "Overexpression of TGR5 alleviates myocardial ischemia/reperfusion injury via AKT/ GSK- $3 \beta$ mediated inflammation and mitochondrial pathway," Bioscience Reports, vol. 40, no. 1, 2020.

[128] J. Wang, J. Zhang, X. Lin et al., "DCA-TGR5 signaling activation alleviates inflammatory response and improves cardiac function in myocardial infarction," Journal of Molecular and Cellular Cardiology, vol. 151, pp. 3-14, 2021.

[129] P. H. Dixon and C. Williamson, "The pathophysiology of intrahepatic cholestasis of pregnancy," Clinics and Research in Hepatology and Gastroenterology, vol. 40, no. 2, pp. 141153, 2016.

[130] R. I. Macias, M. J. Pascual, A. Bravo et al., "Effect of maternal cholestasis on bile acid transfer across the rat placentamaternal liver tandem," Hepatology, vol. 31, no. 4, pp. 975983, 2000.

[131] T. Zhang, C. Zhao, L. Luo et al., "High concentraction of taurocholic acid induced apoptosis in HTR-8/SVneo cells via overexpression of ERp29 and activation of p38," Placenta, vol. 35, no. 7, pp. 496-500, 2014.

[132] T. Joutsiniemi, S. Timonen, R. Leino, P. Palo, and U. Ekblad, "Ursodeoxycholic acid in the treatment of intrahepatic cholestasis of pregnancy: a randomized controlled trial," Archives 
of Gynecology and Obstetrics, vol. 289, no. 3, pp. 541-547, 2014.

[133] L. C. Chappell, J. L. Bell, A. Smith et al., "Ursodeoxycholic acid versus placebo in women with intrahepatic cholestasis of pregnancy (PITCHES): a randomised controlled trial," The Lancet, vol. 394, no. 10201, pp. 849-860, 2019.

[134] J. Fleminger, P. Seed, A. Smith et al., "Ursodeoxycholic acid in intrahepatic cholestasis of pregnancy: a secondary analysis of the PITCHES trial," BJOG, vol. 128, no. 6, pp. 1066-1075, 2021.

[135] Z. X. Yang, W. Shen, and H. Sun, "Effects of nuclear receptor FXR on the regulation of liver lipid metabolism in patients with non-alcoholic fatty liver disease," Hepatology International, vol. 4, no. 4, pp. 741-748, 2010.

[136] M. Mueller, A. Thorell, T. Claudel et al., "Ursodeoxycholic acid exerts farnesoid X receptor-antagonistic effects on bile acid and lipid metabolism in morbid obesity," Journal of Hepatology, vol. 62, no. 6, pp. 1398-1404, 2015.

[137] P. Maloney, D. Parks, C. Haffner et al., "Identification of a chemical tool for the orphan nuclear receptor FXR," Journal of Medicinal Chemistry, vol. 43, no. 16, pp. 2971-2974, 2000.

[138] S. M. W. van de Wiel, I. Bijsmans, S. W. C. van Mil, and S. F. J. van de Graaf, "Identification of FDA-approved drugs targeting the farnesoid X receptor," Scientific Reports, vol. 9, no. 1, article 2193, 2019.

[139] J. Li, M. Liu, Y. Li et al., "Discovery and optimization of nonbile acid FXR agonists as preclinical candidates for the treatment of nonalcoholic steatohepatitis," Journal of Medicinal Chemistry, vol. 63, no. 21, pp. 12748-12772, 2020.

[140] V. Sepe, E. Distrutti, S. Fiorucci, and A. Zampella, "Farnesoid $\mathrm{X}$ receptor modulators 2014-present: a patent review," Expert Opinion on Therapeutic Patents, vol. 28, no. 5, pp. 351-364, 2018.

[141] S. Katsuma, A. Hirasawa, and G. Tsujimoto, "Bile acids promote glucagon-like peptide-1 secretion through TGR5 in a murine enteroendocrine cell line STC-1," Biochemical and Biophysical Research Communications, vol. 329, no. 1, pp. 386-390, 2005.

[142] A. Bronden, A. Alber, U. Rohde et al., "The bile acidsequestering resin sevelamer eliminates the acuteGLP-1 stimulatory effect of endogenously released bile acids in patients with type 2 diabetes," Diabetes, Obesity \& Metabolism, vol. 20, no. 2, pp. 362-369, 2018.

[143] S. De Marino, A. Carino, D. Masullo et al., "Epoxide functionalization on cholane side chains in the identification of G-protein coupled bile acid receptor (GPBAR1) selective agonists," RSC Advances, vol. 7, no. 52, pp. 32877-32885, 2017.

[144] C. D'Amore, F. S. Di Leva, V. Sepe et al., "Design, synthesis, and biological evaluation of potent dual agonists of nuclear and membrane bile acid receptors," Journal of Medicinal Chemistry, vol. 57, no. 3, pp. 937-954, 2014.

[145] R. J. Hodge and D. J. Nunez, "Therapeutic potential of Takeda-G-protein-receptor-5 (TGR5) agonists. Hope or hype?," Diabetes, Obesity \& Metabolism, vol. 18, no. 5, pp. 439-443, 2016.

[146] I. Kythera Biopharmaceuticals, "Kybella ${ }^{\mathrm{TM}}$," 2015, https:// www.accessdata.fda.gov/scripts/cder/daf/.

[147] D. S. Wishart, Y. D. Feunang, A. C. Guo et al., "DrugBank 5.0: a major update to the DrugBank database for 2018," Nucleic Acids Research, vol. 46, no. D1, pp. D1074-D1082, 2018.
[148] M. Kars, L. Yang, M. F. Gregor et al., "Tauroursodeoxycholic acid may improve liver and muscle but not adipose tissue insulin sensitivity in obese men and women," Diabetes, vol. 59, no. 8, pp. 1899-1905, 2010.

[149] M. Seidensticker, R. Seidensticker, R. Damm et al., "Prospective randomized trial of enoxaparin, pentoxifylline and ursodeoxycholic acid for prevention of radiationinduced liver toxicity," PLoS One, vol. 9, no. 11, article e112731, 2014.

[150] S. Nielsen, M. S. Svane, R. E. Kuhre et al., "Chenodeoxycholic acid stimulates glucagon-like peptide-1 secretion in patients after Roux-en-Y gastric bypass," Physiological Reports, vol. 5, no. 3, article e13140, 2017.

[151] M. Hansen, M. Scheltema, D. Sonne et al., "Effect of chenodeoxycholic acid and the bile acid sequestrant colesevelam on glucagon-like peptide-1 secretion," Diabetes, Obesity and Metabolism, vol. 18, no. 6, pp. 571-580, 2016.

[152] S. Paganoni, E. A. Macklin, S. Hendrix et al., "Trial of sodium phenylbutyrate-taurursodiol for amyotrophic lateral sclerosis," The New England Journal of Medicine, vol. 383, no. 10, pp. 919-930, 2020.

[153] S. Paganoni, S. Hendrix, S. P. Dickson et al., "Long-term survival of participants in the CENTAUR trial of sodium phenylbutyrate-taurursodiol in amyotrophic lateral sclerosis," Muscle Nerve, vol. 63, no. 1, pp. 31-39, 2021.

[154] J. R. Walters, I. M. Johnston, J. D. Nolan, C. Vassie, M. E. Pruzanski, and D. A. Shapiro, "The response of patients with bile acid diarrhoea to the farnesoid X receptor agonist obeticholic acid," Alimentary Pharmacology \& Therapeutics, vol. 41, no. 1, pp. 54-64, 2015.

[155] M. Camilleri, S. L. Nord, D. Burton et al., "Randomised clinical trial: significant biochemical and colonic transit effects of the farnesoid $\mathrm{X}$ receptor agonist tropifexor in patients with primary bile acid diarrhoea," Alimentary Pharmacology \& Therapeutics, vol. 52, no. 5, pp. 808-820, 2020.

[156] B. A. Neuschwander-Tetri, R. Loomba, A. J. Sanyal et al., "Farnesoid X nuclear receptor ligand obeticholic acid for non-cirrhotic, non- alcoholic steatohepatitis (FLINT): a multicentre, randomised, placebo- controlled trial," The Lancet, vol. 385, no. 9972, pp. 956-965, 2015.

[157] S. Traussnigg, J. M. Schattenberg, M. Demir et al., "Norursodeoxycholic acid versus placebo in the treatment of nonalcoholic fatty liver disease: a double-blind, randomised, placebo-controlled, phase 2 dose- finding trial," The Lancet Gastroenterology \& Hepatology, vol. 4, no. 10, pp. 781-793, 2019.

[158] S. Mudaliar, R. R. Henry, A. J. Sanyal et al., "Efficacy and safety of the farnesoid $\mathrm{X}$ receptor agonist obeticholic acid in patients with type 2 diabetes and nonalcoholic fatty liver disease," Gastroenterology, vol. 145, no. 3, pp. 574-582.e1, 2013.

[159] M. Trauner, F. Nevens, M. L. Shiffman et al., "Long-term efficacy and safety of obeticholic acid for patients with primary biliary cholangitis: 3-year results of an international openlabel extension study," The Lancet Gastroenterology \& Hepatology, vol. 4, no. 6, pp. 445-453, 2019.

[160] K. V. Kowdley, V. Luketic, R. Chapman et al., “A randomized trial of obeticholic acid monotherapy in patients with primary biliary cholangitis," Hepatology, vol. 67, no. 5, pp. 1890-1902, 2018.

[161] P. Fickert, G. M. Hirschfield, G. Denk et al., “_nor_Ursodeoxycholic acid improves cholestasis in primary sclerosing 
cholangitis," Journal of Hepatology, vol. 67, no. 3, pp. 549558, 2017.

[162] T. Li, S. R. Holmstrom, S. Kir et al., "The G protein-coupled bile acid receptor, TGR5, stimulates gallbladder filling," Molecular Endocrinology, vol. 25, no. 6, pp. 1066-1071, 2011.

[163] R. M. Fryer, K. J. Ng, S. G. Nodop Mazurek et al., "G proteincoupled bile acid receptor 1 stimulation mediates arterial vasodilation through a KCa1.1 (BKCa)-Dependent mechanism," The Journal of Pharmacology and Experimental Therapeutics, vol. 348, no. 3, pp. 421-431, 2014.

[164] H. Duan, M. Ning, Q. Zou et al., "Discovery of intestinal targeted TGR5 agonists for the treatment of type 2 diabetes," Journal of Medicinal Chemistry, vol. 58, no. 8, pp. 3315$3328,2015$.

[165] S. Al-Dury, A. Wahlstrom, K. Panzitt et al., "Obeticholic acid may increase the risk of gallstone formation in susceptible patients," Journal of Hepatology, vol. 71, no. 5, pp. 986-991, 2019.

[166] J. E. Eaton, M. G. Silveira, D. S. Pardi et al., "High-dose ursodeoxycholic acid is associated with the development of colorectal neoplasia in patients with ulcerative colitis and primary sclerosing cholangitis," The American Journal of Gastroenterology, vol. 106, no. 9, pp. 1638-1645, 2011.

[167] E. Wunsch, J. Trottier, M. Milkiewicz et al., "Prospective evaluation of ursodeoxycholic acid withdrawal in patients with primary sclerosing cholangitis," Hepatology, vol. 60, no. 3, pp. 931-940, 2014.

[168] T. Pearson, J. G. Caporaso, M. Yellowhair et al., "Effects of ursodeoxycholic acid on the gut microbiome and colorectal adenoma development," Cancer Medicine, vol. 8, no. 2, pp. 617-628, 2019.

[169] S. Miyata, Y. Kawashima, M. Sakai et al., "Discovery, optimization, and evaluation of non-bile acid FXR/TGR5 dual agonists," Scientific Reports, vol. 11, no. 1, p. 9196, 2021.

[170] X. X. Wang, D. Wang, Y. Luo et al., "FXR/TGR5 dual agonist prevents progression of nephropathy in diabetes and obesity," Journal of the American Society of Nephrology, vol. 29, no. 1, pp. 118-137, 2018.

[171] X. X. Wang, Y. Luo, D. Wang et al., "A dual agonist of farnesoid $\mathrm{X}$ receptor (FXR) and the G protein-coupled receptor TGR5, INT-767, reverses age-related kidney disease in mice," The Journal of Biological Chemistry, vol. 292, no. 29, pp. 12018-12024, 2017.

[172] Y. B. Hu, X. Y. Liu, and W. Zhan, "Farnesoid X receptor agonist INT-767 attenuates liver steatosis and inflammation in rat model of nonalcoholic steatohepatitis," Drug Design, Development and Therapy, vol. 12, pp. 2213-2221, 2018.

[173] J. Roth, M. Feigh, S. Veidal et al., "INT-767 improves histopathological features in a diet-inducedob/obmouse model of biopsy-confirmed non-alcoholic steatohepatitis," World Journal of Gastroenterology, vol. 24, no. 2, pp. 195210, 2018. 